\title{
IMPACTO DO MANEJO CONVENCIONAL SOBRE PROPRIEDADES FÍSICAS E SUBSTÂNCIAS HÚMICAS DE SOLOS SOB CERRADO
}

\author{
IMPACT OF CONVENTIONAL MANAGEMENT UPON BOTH PHYSICAL PROPERTIES AND \\ HUMIC SUBSTANCES OF SOILS UNDER CERRADO
}

\author{
Tony Jarbas Ferreira Cunha ${ }^{1}$ José Ronaldo Macedo ${ }^{1}$ Lucedino Paixão Ribeiro ${ }^{2}$ \\ Francesco Palmieri $^{1}$ Pedro Luiz de Freitas ${ }^{1}$ Ariomar de Castro Aguiar $^{3}$
}

RESUMO

A utilização do manejo convencional em solos sob cerrado tem acarretado modificações nas suas propriedades, bem como no comportamento e qualidade da sua matéria orgânica. $O$ objetivo desta pesquisa foi investigar o impacto do manejo convencional nas propriedades físicas e no conteúdo e qualidade de substâncias húmicas de um Latossolo Vermelho-Amarelo, originalmente sob cerrado. $O$ estudo foi realizado em uma propriedade agrícola no município de São Desidério-BA. Foram avaliadas quatro áreas sob diferentes períodos de uso e uma sob cerrado nativo. Os tempos de uso foram de um, dois, três e seis anos, sendo que a área estudada após seis anos passou por um período de três anos de pousio. O sistema de preparo do solo utilizado foi o tradicional da região, que consiste no uso de duas passadas de grade pesada aradora e duas de grade niveladora. Também foram realizadas, na ocasião de cada plantio, uma adubação com $N-P-K+$ micronutrientes e calagens com base em resultados de análise de solo. As áreas foram cultivadas com milho e soja em sistema de rotação. Verificou-se que o manejo adotado não foi sustentável, pois já nos primeiros três anos de uso agrícola, ocorreu grande deterioração das propriedades físicas do solo, como densidade, porosidade e conteúdo de água disponível. $O$ processo de humificação e a qualidade da matéria orgânica foram influenciados pela aplicação de calcário e pela rotação de culturas (milho/soja) e, ainda, que o sistema de manejo utilizado mostrou-se mais benéfico para o processo de estabilização das substâncias húmicas do que para as propriedades físicas dos solos estudados.

Palavras-chave: manejo de solo, substâncias húmicas, cerrados, Latossolo Vermelho-Amarelo.

\section{SUMMARY}

The utilization of intensive conventional management system on soils under cerrado biome has caused modification in their properties, as well as, in the behavior and quality of the organic matter. The objective of this research was to evaluate the impact of conventional soil management practices upon physical properties, contents and qualities of humic substances of a Red-Yellow Oxisol, formerly, under cerrado (savana-like) natural vegetation. The study was accomplished on an private agricultural property in the municipal district of São Desidério-BA. They were appraised four areas under different length of times of agricultural use and one area under native cerrado (savana-like). The length of time under agriculture use was one, two, three and six years, and after six years the studied area was left uncultivated for a period of three years. The soil has been prepared under traditional systems which consists of plowing the land twice with heavy disks followed by twice grading. It was also applied, during the seedling time, $N-P-K$ fertilizer plus micronutrients and lime according to soil analysis. The areas have been cultivated with corn and soybeans in a rotation system. It was observed that the adopted management system was not sustainable, because, at the first three years under cultivation occurred a great deterioration of physical properties such as soil density, porosity and available water contents. The humification process and the quality of the organic matter were influenced by both utilization of lime and by the rotation system (corn/soybeans). The used system was more benefic for the process of stabilization of the humic substances than for the physical properties of the studied soils.

Key words: soil management, soil humic substances, cerrado biome, Red-Yellow Oxisol.

\section{INTRODUÇÃO}

Quando o homem altera o equilíbrio do ecossistema, ocorre mudanças na dinâmica da matéria orgânica e os efeitos dessa perturbação são, geralmente, negativos para as propriedades físicas,

\footnotetext{
${ }^{1}$ Engenheiro Agrônomo, Pesquisador da Embrapa Solos, Rua Jardim Botânico 1024, 22460-000, Rio de Janeiro, RJ. E-mail: tony@cnps.embrapa.br. Autor para correspondência.

${ }^{2}$ Professor, Doutor do Departamento de Geoquímica e Meio Ambiente da Universidade Federal da Bahia, IGG, Salvador, Ba.

${ }^{3}$ Pesquisador da Empresa Baiana de Pesquisa Agropecuária, EBDA, Barreiras, BA.
} 
químicas e biológicas dos solos. Quando manejada, a fração orgânica não apresenta a mesma estabilidade das frações minerais. Sob uso agrícola, a utilização intensiva da terra com sistemas de cultivos inadequados tem contribuído para a degradação das características físicas, químicas e biológicas do solo. Particularmente, a diminuição da estabilidade de agregados naturais; o aumento da densidade e a diminuição da macroporosidade, tamanho de agregados e da taxa de infiltração de água, além de redução no complexo de cargas e na atividade biológica têm sido demonstrados (SOUZA \& COGO, 1978; MACHADO et al., 1981; ROOSE et al., 1993; SILVA \& MIELNICZUK, 1997). Essa degradação da qualidade do solo está diretamente relacionada à diminuição do teor de matéria orgânica e à compactação pelo tráfego (DALLA ROSA, 1981; BLANCANEAUX et al., 1993).

Com a abertura de novas áreas agrícolas na região central do Brasil, os solos sob vegetação de cerrados foram rapidamente incorporados ao processo produtivo. No oeste baiano, esses solos somam, aproximadamente, cinco milhões de hectares passíveis de serem cultivados. A cobertura pedológica predominante é constituída por solos de textura arenosa e média, excessivamente drenados e com capacidade de troca de cátions (CTC) menor que $5 \mathrm{cmol}_{\mathrm{c}} / \mathrm{kg}^{-1}$. Nessas condições, $80 \%$ da CTC pode ser atribuída à participação da matéria orgânica, refletindo, dessa forma, a importância desse componente no processo produtivo. A condição edafo-ambiental existente favorece a agricultura intensiva com a utilização de discos (grade pesada e arado), complementada com a utilização de subsoladores e escarificadores, necessários para "quebrar" os impedimentos físicos (FREITAS, 1992). Apesar do crescente número de trabalhos versando sobre a matéria orgânica do solo, o conhecimento é ainda incipiente, principalmente no que se refere à sua influência em processos de estruturação e de retenção de cátions em latossolos da região sob vegetação de Cerrados (FREITAS et $\boldsymbol{a l}$., 1998a). Acredita-se que o conhecimento do comportamento de substâncias húmicas de solos sob cerrados possa conduzir ao entendimento dos processos de evolução e degradação desses solos, bem como subsidiar os sistemas de manejo conservacionistas a serem aplicados aos mesmos.

Considerando-se que a dinâmica do processo de humificação da matéria orgânica dos solos está diretamente relacionada à sua evolução superficial e condicionada pelo manejo, o presente trabalho teve como objetivo verificar o impacto do manejo convencional nas propriedades físicas e no conteúdo e qualidade das substâncias húmicas num Latossolo Vermelho-Amarelo, originalmente sob cerrado.

\section{MATERIAL E MÉTODOS}

O estudo foi realizado em uma propriedade rural localizada no município de São Desidério, região de domínio da vegetação de Cerrado, no Oeste Baiano. O clima é classificado como Aw da classificação de Köppen, com temperaturas médias anuais de $24^{\circ} \mathrm{C}$, e precipitação média anual de 1.200 $\mathrm{mm}$, distribuídos entre os meses de novembro e março, tendo, também, um período seco bem definido entre abril e setembro.

Foram selecionadas cinco parcelas em áreas com características morfopedológicas semelhantes em um Latossolo Vermelho-Amarelo A, moderado, textura média, incluindo áreas com vegetação nativa de Cerrado e cultivadas com soja e milho em rotação por diferentes períodos de cultivo e de pousio, após desmatamento manual com queimada. Os tratamentos selecionados foram: $T n-$ solo em área em condição de vegetação nativa, considerada testemunha; $T 1$ - solo com 1 ano de cultivo de soja; T2 - solo com 2 anos de cultivo (soja-milho); T3 - solo com 3 anos de cultivo (soja-milho-soja); e, $T p$ - solo com 1 ano de cultivo (soja) após 2 anos de cultivo e 3 anos de pousio não manejado (vegetação espontânea).

Nas áreas cultivadas com soja e milho, o preparo do solo constituiu de duas gradagens com grade aradora e duas, com grade niveladora. $\mathrm{Na}$ ocasião de cada plantio, foi efetuada uma adubação $\mathrm{N}-\mathrm{P}-\mathrm{K}+$ micronutrientes, com base na análise do solo. As calagens foram realizadas dois meses antes do plantio das culturas, em cada ano, utilizando-se 3t/ha de calcário calcítico.

Em cada parcela, foi descrito um perfil de solo, em locais selecionados, com a mesma posição topográfica de chapada. A descrição pedológica dos perfis foi baseada em LEMOS \& SANTOS (1984). A amostragem foi realizada nos horizontes identificados durante a descrição, e as análises foram feitas nos laboratórios da Empresa Baiana de Desenvolvimento Agrícola - EBDA, em Barreiras, BA.

A granulometria do solo foi determinada pelo método da pipeta adaptado (EMBRAPA, 1998), e a densidade de partículas, pelo método do balão volumétrico com álcool etílico (EMBRAPA, 1998). A densidade do solo e a curva de retenção de água foram determinados em amostras indeformadas, coletadas em anéis volumétricos de $100 \mathrm{~cm}^{3}$, verticalmente no centro dos horizontes diagnosticados. A curva de retenção de água no solo foi determinada submetendo as amostras, após saturação, a tensões de 0,$01 ; 0,03 ; 0,1 ;$ e, $1,5 \mathrm{MPa}$, pelo aparelho extrator de Richards (EMBRAPA, 1998) para determinação da umidade e da disponibilidade de água no solo. A 
disponibilidade de água no solo foi calculada como sendo a umidade retida entre as tensões de $0,1 \mathrm{MPa}$ e $1,5 \mathrm{MPa}$ por horizonte diagnóstico, sendo posteriormente ajustada para os intervalos de profundidade, através do somatório da lâmina de água (em $\mathrm{mm} / \mathrm{cm}$ ) para cada intervalo de $20 \mathrm{~cm}$, segundo a fórmula:

$$
\mathrm{AD}_{20 \mathrm{~cm}}=(\text { A.D. } \div \text { espessura do horizonte }) \times 20 \mathrm{~cm}
$$

A distribuição de tamanho de poros (DTP) foi determinada a partir da curva de retenção de água no solo, em função do diâmetro equivalente $\left(d_{e}\right)$ com base em FREITAS \& BLANCANEAUX (1994), utilizado a classificação proposta por FREITAS $\boldsymbol{e t}$ al. (1998b), como segue:

microporosidade ou porosidade textural $\left(\mathrm{d}_{\mathrm{e}}<0,2\right.$ $\mu \mathrm{m})$;

mesoporosidade ou porosidade estrutural argilosa $\left(0,2<\mathrm{d}_{\mathrm{e}}<9 \mu \mathrm{m}\right)$

macroporosidade ou porosidade estrutural $\left(\mathrm{d}_{\mathrm{e}}>9\right.$ $\mu \mathrm{m})$.

Os atributos morfoestruturais foram avaliados no campo, utilizando-se a metodologia do perfil cultural conforme descrito em FREITAS et al (1998b)

As substâncias húmicas foram fracionadas em ácidos fúlvicos livres (AFL), ácidos fúlvicos $(\mathrm{AF})$, ácidos húmicos $(\mathrm{AH})$ e huminas (HU). O fracionamento foi realizado conforme os princípios do método de DABIN (1971), cujo protocolo é o seguinte: os AFL foram extraídos com ácido fosfórico $2 \mathrm{~mol} / \ell^{-1}$; AF e AH, com solução de pirofosfato de sódio $0,1 \mathrm{~mol} / \ell^{-1} \mathrm{e}$, posteriormente, com solução de hidróxido de sódio $0,1 \mathrm{~mol} / \ell^{-1}$, ambos numa relação solo/extrator de 1:20; o tratamento do extrato com ácido sulfúrico $1 \mathrm{~mol} / \ell^{-1}$ permitiu separar os $\mathrm{AF}$, que permaneceram em solução, dos AH, que precipitaram. As HU corresponderam ao resíduo no tubo de centrífuga, pois não são solúveis em ácidos ou bases. Devido à baixa quantidade, os resíduos vegetais leves (RVL) foram obtidos por diferença entre o teor de carbono orgânico total e o carbono correspondente à soma das frações anteriormente descrita. $\mathrm{O}$ teor de carbono orgânico em cada fração foi determinado por oxidação sulfocrômica, conforme (EMBRAPA, 1998)

\section{RESULTADOS E DISCUSSÃO}

\section{Propriedades morfoestruturais}

Todos os perfis foram classificados como Latossolo Vermelho-Amarelo álico A moderado textura média fase cerrado relevo plano e apresenta- ram seqüência de horizontes $\mathrm{A}$ ou $\mathrm{Ap}, \mathrm{AB}$ e $\mathrm{Bw}$. O perfil sob cerrado nativo (Tn) apresentou um horizonte orgânico (Oo) de dois centímetros de espessura, formado por uma serrapilheira de detritos vegetais pouco decompostos. Devido ao preparo do solo necessário para o cultivo, o horizonte Oo da mata nativa foi queimado e/ou incorporado ao horizonte A subjacente, ajudando na formação do horizonte Ap nos perfis cultivados. Os horizontes superficiais e subsuperficiais não apresentaram grandes variações com relação às suas cores e espessuras.

As principais modificações morfológicas resultantes do cultivo contínuo do solo são relacionadas à transição e estrutura dos horizontes superficiais. A transição passou de gradual, no horizonte $\mathrm{A}_{2}$ do perfil sob mata nativa, para clara, no horizonte Ap dos perfis cultivados. No que concerne à estrutura, o horizonte superficial do perfil Tn apresentou uma estrutura forte pequena granular, enquanto no Ap do T1 apresentou estrutura fraca pequena granular e blocos subangulares, indicando que o desmatamento e o cultivo exerceram efeito imediato no grau de estruturação do solo. Nos perfis T2, T3 e Tp, verificou-se que o cultivo proporcionou ligeira melhora, com o passar dos anos, no grau de estruturação do solo, em relação ao perfil T1, o que, provavelmente, pode ser atribuído ao sistema radicular fasciculado do milho.

Em todos os perfis cultivados, os horizontes superficiais apresentaram-se ligeiramente duros a duros, enquanto o perfil sob cerrado nativo, apresentou consistência solta a macia.

\section{Propriedades físicas}

Granulometria: em todas as áreas ocorreu um predomínio da fração areia fina em todos os perfis, com valores que variaram de 511 a $633 \mathrm{~g} / \mathrm{kg}^{-1}$ (Tabela 1). Os teores totais de areia (areia fina + areia grossa) variaram entre 703 e $851 \mathrm{~g} / \mathrm{kg}^{-1}$, o que indica uma fragilidade do sistema como um todo. Os teores de argila foram, por consequiência, muito baixos, variando entre $115 \mathrm{~g} / \mathrm{kg}^{-1}$, nos horizontes superficiais, a $243 \mathrm{~g} / \mathrm{kg}^{-1}$ nos subsuperficiais. Foi observada uma tendência de acumulação de argila no horizonte $\mathrm{A}_{2}$ do perfil Tn. Os perfis T3 e Tp apresentaram os menores teores de argila, sendo que o segundo apresentou as menores relações areia fina/areia grossa, o que deve afetar suas propriedades físicas. Sob o ponto de vista da manutenção do conteúdo da matéria orgânica, o baixo teor de argila observado nos perfis é bastante desfavorável (DUCHAUFOUR, 1977).

Com relação ao tempo de cultivo, ocorreu um incremento da fração argila nos horizontes dos perfis T1 e T2, ocorrendo, posteriormente, uma 
Tabela 1 - Granulometria do solo nos cinco perfis estudados.

\begin{tabular}{|c|c|c|c|c|c|}
\hline \multicolumn{2}{|c|}{ Horizontes } & \multicolumn{4}{|c|}{ Frações granulométricas } \\
\hline \multirow[t]{2}{*}{ Símbolo } & Espessura & Areia grossa & Areia fina & Silte & Argila \\
\hline & $\mathrm{cm}$ & \multicolumn{4}{|c|}{ - } \\
\hline \multicolumn{6}{|c|}{ Perfil Tn - solo sob cerrado nativo } \\
\hline A1 & $0-10$ & 329 & 511 & 33 & 127 \\
\hline $\mathrm{A} 2$ & $10-20$ & 242 & 566 & 39 & 153 \\
\hline $\mathrm{AB}$ & $20-40$ & 258 & 582 & 43 & 117 \\
\hline Bw1 & $40-55$ & 262 & 530 & 45 & 163 \\
\hline Bw2 & $55-80$ & 237 & 528 & 37 & 198 \\
\hline Bw3 & $80-110$ & 227 & 528 & 40 & 205 \\
\hline Bw4 & $110-135^{+}$ & 221 & 515 & 44 & 220 \\
\hline \multicolumn{6}{|c|}{ Perfil T1 - solo com um ano de cultivo de soja } \\
\hline Ap & $0-15$ & 224 & 561 & 58 & 157 \\
\hline $\mathrm{AB}$ & $15-30$ & 210 & 591 & 66 & 133 \\
\hline Bw1 & $30-50$ & 176 & 584 & 65 & 175 \\
\hline Bw2 & $50-80$ & 159 & 564 & 52 & 225 \\
\hline Bw3 & $80-110$ & 159 & 552 & 47 & 242 \\
\hline Bw4 & $110-135^{+}$ & 152 & 553 & 52 & 243 \\
\hline \multicolumn{6}{|c|}{ Perfil T2 - solo com dois anos de cultivo (soja-milho) } \\
\hline Ap & $0-15$ & 220 & 559 & 49 & 172 \\
\hline $\mathrm{AB}$ & $15-30$ & 203 & 537 & 73 & 151 \\
\hline Bw1 & $30-45$ & 182 & 571 & 68 & 179 \\
\hline Bw2 & $45-65$ & 176 & 561 & 60 & 203 \\
\hline Bw3 & $65-105$ & 166 & 537 & 55 & 242 \\
\hline Bw4 & $105-130^{+}$ & 171 & 537 & 56 & 236 \\
\hline \multicolumn{6}{|c|}{ Perfil T3 - solo com três anos de cultivo (soja-milho) } \\
\hline Ap1 & $0-10-$ & 258 & 593 & 34 & 115 \\
\hline Ap2 & $10-25$ & 220 & 612 & 44 & 124 \\
\hline $\mathrm{AB}$ & $25-45$ & 196 & 633 & 39 & 132 \\
\hline Bw1 & $45-80$ & 184 & 609 & 45 & 162 \\
\hline Bw2 & $80-110$ & 176 & 606 & 46 & 172 \\
\hline Bw3 & $110-135^{+}$ & 182 & 594 & 46 & 178 \\
\hline
\end{tabular}

Perfil Tp - solo com um ano de cultivo após três anos de pousio

\begin{tabular}{lccccc} 
Ap & $0-25$ & 277 & 556 & 37 & 130 \\
$\mathrm{Ab}$ & $25-35$ & 295 & 532 & 37 & 136 \\
$\mathrm{Bw} 1$ & $35-50$ & 268 & 539 & 42 & 151 \\
$\mathrm{Bw} 2$ & $50-75$ & 260 & 531 & 30 & 179 \\
$\mathrm{Bw} 3$ & $75-105$ & 243 & 527 & 37 & 193 \\
$\mathrm{Bw} 4$ & $105-120^{+}$ & 232 & 528 & 42 & 198 \\
\hline
\end{tabular}

redistribuição nos valores do perfil (T3) em relação ao sob mata (Tabela 1). Esse fato, pode ser devido à dispersão da argila provocada pelo preparo do solo, que age promovendo a degradação dos teores de matéria orgânica e, conseqüentemente, desagregando a estrutura do solo, tendo em vista que os perfis ocupam a mesma posição topográfica de chapada, ou mais provavelmente pelo uso de calcário em quantidades elevadas (caso da área estudada), que pode promover, neste caso, a dispersão da argila, conforme demonstrado por JUCKSCH et al (1986).

Densidade do solo: ocorreu uma tendência de aumento da densidade do solo nos horizontes superficiais e subsuperficiais, nos perfis cultivados
T1, T2 e T3, (Tabela 2), a qual, provavelmente, foi decorrente da ação de implementos agrícolas utilizados (arados e grades), seja pulverizando os horizontes superficiais e aumentando a densidade de acomodação do solo, seja promovendo a compactação mecânica dos horizontes subsuperficiais (pé de grade/arado). No perfil T3 e Tp, esse efeito é igualmente importante, mantidas as proporções e considerando o efeito da textura mais arenosa. Pereira et al. (1994) também verificaram em um Latossolo VermelhoEscuro, que, após dez anos de cultivo, a densidade do solo variou de $0,88 \mathrm{Mgm}^{-3}$ a $1,03 \mathrm{Mgm}^{-3}$ (variação de $0,15 \mathrm{Mgm}^{-3}$ ), demonstrando o efeito do manejo intensivo do solo, adensando os horizontes superficiais e causando possíveis limitações ao desenvolvimento de plantas (KIEHL, 1979) e ao crescimento de raízes.

Verificou-se também um aumento dos valores de densidade do solo abaixo do horizonte $\mathrm{AB}$ nos perfis $\mathrm{T} 2$ e $\mathrm{T} 3$, demonstrando que a transmissão da pressão de compactação ocorreu primeiro nos horizontes superficiais, para, em seguida, ser transmitida para os horizontes inferiores. Segundo KER et al. (1996), o uso intensivo do solo normalmente induz à compactação com redução da porosidade total e dos microporos, diminuindo, assim, a capacidade de adsorção e retenção de água. No entanto, neste trabalho observou-se que em solos arenosos e de textura média ocorreu um aumento da profundidade da camada compactada com o tempo de cultivo. Segundo COSTA (1985); COSTA \& JUCKSCH (1992); KER et al. (1992), citados por KER et al. (1996), os Latossolos da região dos cerrados, utilizados intensivamente na produção de soja, milho e feijão degradam-se fisicamente com o tempo de uso. Pode-se verificar também que os valores de densidade do solo diminuíram quando se comparou os perfis Tp e T3, considerando sua similaridade em textura. Isso, provavelmente, devese à ação mecânica exercida pelas raízes das plantas que colonizaram o solo durante o pousio no perfil Tp.

Porosidade: a porosidade total não foi alterada até o segundo ano de plantio (T2), quando comparado à mata $(\mathrm{Tn})$. Entretanto, a partir do terceiro ano (T3), verificou-se uma sensível diminuição nos valores da porosidade total, atingindo perda de até $7 \%$ (Tabela 2). Esses dados confirmam os resultados obtidos por PREVEDELLO (1996), em que o uso inadequado do solo afetou a porosidade, tendo como consequiências a redução no armazenamento, disponibilidade e transporte da solução e do ar do 
Tabela 2 - Propriedades físicas dos perfis estudados.

\begin{tabular}{|c|c|c|c|c|c|c|c|c|}
\hline Horiz. & Prof. & $\begin{array}{l}\text { Densidade } \\
\text { aparente }\end{array}$ & $\begin{array}{c}\text { Densidade } \\
\text { real }\end{array}$ & $\begin{array}{l}\text { Porosidade } \\
\text { total }\end{array}$ & $\begin{array}{l}\text { Umidade } \\
0,01\end{array}$ & $\begin{array}{l}\text { Umidade } \\
0,03\end{array}$ & $\begin{array}{c}\text { Umidade } \\
0,1\end{array}$ & Umidade \\
\hline & $\mathrm{cm}$ & $\mathrm{G} / \mathrm{cm}^{3}$ & $\mathrm{G} / \mathrm{cm}^{3}$ & $\%$ & -------- & ------ M & ------- & ----- \\
\hline \multicolumn{9}{|c|}{ Perfil Tn - solo sob cerrado nativo } \\
\hline A1 & $0-10$ & 1,40 & 2,40 & 42 & 9,36 & 7,06 & 6,23 & 4,28 \\
\hline $\mathrm{A} 2$ & $10-20$ & 1,41 & 2,49 & 43 & 7,50 & 5,63 & 4,74 & 3,96 \\
\hline $\mathrm{AB}$ & $20-40$ & 1,49 & 2,66 & 44 & 7,64 & 5,76 & 5,15 & 4,07 \\
\hline Bw1 & $40-55$ & 1,46 & 2,49 & 41 & 9,23 & 6,97 & 6,34 & 5,13 \\
\hline Bw2 & $55-80$ & 1,45 & 2,72 & 47 & 10,44 & 8,04 & 7,13 & 5,69 \\
\hline Bw3 & $80-110$ & 1,48 & 2,54 & 42 & 10,90 & 8,15 & 7,11 & 5,92 \\
\hline Bw4 & $110-135^{+}$ & 1,47 & 2,67 & 45 & 12,24 & 8,95 & 7,52 & 6,23 \\
\hline \multicolumn{9}{|c|}{ Perfil T1 - solo com um ano de cultivo de soja } \\
\hline Ap & $0-15$ & 1,49 & 2,65 & 44 & 12,48 & 8,98 & 7,32 & 4,97 \\
\hline $\mathrm{AB}$ & $15-30$ & 1,49 & 2,65 & 44 & 9,89 & 7,57 & 6,63 & 5,04 \\
\hline Bw1 & $30-50$ & 1,47 & 2,64 & 44 & 11,12 & 8,66 & 7,61 & 5,84 \\
\hline $\mathrm{Bw} 2$ & $50-80$ & 1,47 & 2,70 & 45 & 13,11 & 9,28 & 8,15 & 6,52 \\
\hline Bw3 & $80-110$ & 1,46 & 2,62 & 42 & 13,96 & 9,66 & 7,99 & 6,54 \\
\hline Bw4 & $110-135^{+}$ & 1,47 & 2,71 & 46 & 14,38 & 9,87 & 8,16 & 6,63 \\
\hline \multicolumn{9}{|c|}{ Perfil T2 - solo com dois anos de cultivo (soja-milho) } \\
\hline Ap & $0-15$ & 1,50 & 2,70 & 45 & 13,30 & 9,54 & 7,57 & 5,69 \\
\hline $\mathrm{AB}$ & $15-30$ & 1,50 & 2,72 & 45 & 11,01 & 8,34 & 7,02 & 5,71 \\
\hline Bw1 & $30-45$ & 1,50 & 2,63 & 43 & 11,44 & 8,57 & 7,33 & 5,95 \\
\hline $\mathrm{Bw} 2$ & $45-65$ & 1,47 & 2,54 & 42 & 11,58 & 9,00 & 7,49 & 6,69 \\
\hline Bw3 & $65-105$ & 1,46 & 2,55 & 43 & 13,67 & 10,10 & 8,19 & 7,14 \\
\hline Bw4 & $105-130^{+}$ & 1,46 & 2,40 & 39 & 13,02 & 9,56 & 7,94 & 6,92 \\
\hline \multicolumn{9}{|c|}{ Perfil T3 - solo com três anos de cutivo (soja-milho-soja) } \\
\hline Ap1 & $0-10$ & 1,59 & 2,50 & 36 & 9,62 & 6,32 & 5,00 & 3,70 \\
\hline Ap2 & $10-25$ & 1,58 & 2,54 & 38 & 9,08 & 6,09 & 4,86 & 3,99 \\
\hline $\mathrm{AB}$ & $25-45$ & 1,57 & 2,61 & 40 & 8,74 & 5,93 & 4,99 & 4,28 \\
\hline Bw1 & $45-80$ & 1,54 & 2,66 & 42 & 10,31 & 6,98 & 5,67 & 4,83 \\
\hline $\mathrm{Bw} 2$ & $80-110$ & 1,57 & 2,59 & 39 & 11,10 & 7,38 & 5,86 & 4,89 \\
\hline Bw3 & $110-135+$ & 1,58 & 2,54 & 38 & 11,77 & 7,92 & 6,00 & 5,03 \\
\hline \multicolumn{9}{|c|}{ Perfil Tp - solo com um ano de cultivo após três anos de pousio } \\
\hline Ap & $0-25$ & 1,53 & 2,67 & 43 & 9,74 & 7,46 & 5,65 & 4,12 \\
\hline $\mathrm{AB}$ & $25-35$ & 1,52 & 2,64 & 43 & 8,75 & 6,41 & 5,63 & 4,99 \\
\hline Bw1 & $35-50$ & 1,50 & 2,59 & 42 & 8,89 & 6,92 & 5,99 & 4,75 \\
\hline $\mathrm{Bw} 2$ & $50-75$ & 1,51 & 2,61 & 42 & 9,89 & 7,23 & 6,17 & 4,91 \\
\hline Bw3 & $75-105$ & 1,53 & 2,62 & 42 & 11,31 & 8,10 & 6,87 & 5,40 \\
\hline Bw4 & $105-120^{+}$ & 1,52 & 2,70 & 44 & 11,12 & 8,10 & 6,99 & 5,42 \\
\hline
\end{tabular}

solo, os quais não só dependem da porosidade total, mas também, e principalmente, de como o espaço total é distribuído por tamanho.

O comportamento da porosidade foi semelhante ao da densidade do solo, pois após o período de pousio ( $\mathrm{Tp}$ ), os valores de porosidade retornaram aos valores aproximados do perfil sob mata (Tn) (Tabela 2 ), já que esses parâmetros estão direta e inversamente correlacionados.

Os valores de distribuição do tamanho dos poros obtidos para três classes de porosidade consideradas (Tabela 3) mostram a predominância de macroporos $\left(d_{e}>9 \mu \mathrm{m}\right)$, característica de solos de textura arenosa, os quais variaram entre 25,2 e $35,4 \%$ do volume total do solo, o que não constitui restrição à aeração e ao movimento de água no solo (FREITAS et al., 1998b). Os microporos ( $\mathrm{d}_{\mathrm{e}}<$ $0,2 \mu \mathrm{m}$ ) variaram entre 5,6 e $10,4 \%$, aumentando em profundidade em todos os perfis estudados, com volumes relativamente menores em T3 e Tp. Em se analisando os perfis cultivados, em relação a Tn, verifica-se um aumento da microporosidade com os anos de cultivo (T1 e T2). Da mesma forma, observa-se um decréscimo da macroporosidade. Um incremento na macroporosidade, como efeito do período de três anos de pousio (perfil Tp), pode ser verificado quando comparado com o perfil T3. Já a variação observada na mesoporosidade $\left(0,2<\mathrm{d}_{\mathrm{e}}<\right.$ $9 \mu \mathrm{m})$ vai refletir na disponibilidade de água no solo, uma vez que é determinada entre a capacidade de campo e o ponto de murcha permanente. 
Tabela 3 - Distribuição de tamanho de poros ( \%) baseado na curva de retenção de umidade.

\begin{tabular}{|c|c|c|c|}
\hline Horizontes & $\begin{array}{l}\text { microporos* } \\
<0,2 \mu \mathrm{m}\end{array}$ & $\begin{array}{l}\text { mesoporos* } \\
0,2-9 \mu \mathrm{m}\end{array}$ & $\begin{array}{c}\text { macroporos* } \\
>9 \mu \mathrm{m}\end{array}$ \\
\hline \multicolumn{4}{|c|}{ Perfil Tn - solo sob cerrado nativo } \\
\hline A1 & 6,0 & 3,9 & 31,8 \\
\hline $\mathrm{A} 2$ & 5,6 & 2,4 & 35,4 \\
\hline $\mathrm{AB}$ & 6,1 & 2,5 & 35,4 \\
\hline Bw1 & 7,5 & 2,7 & 31,2 \\
\hline Bw2 & 8,3 & 3,4 & 35,0 \\
\hline Bw3 & 8,8 & 3,3 & 29,7 \\
\hline Bw4 & 9,2 & 4,0 & 31,8 \\
\hline \multicolumn{4}{|c|}{ Perfil T1 - solo com um ano de cultivo de soja } \\
\hline Ap & 7,4 & 6,0 & 30,4 \\
\hline $\mathrm{AB}$ & 7,5 & 3,8 & 32,5 \\
\hline Bw1 & 8,6 & 4,1 & 31,6 \\
\hline Bw2 & 9,6 & 4,1 & 31,9 \\
\hline Bw3 & 9,5 & 4,6 & 30,2 \\
\hline Bw4 & 9,7 & 4,8 & 31,2 \\
\hline \multicolumn{4}{|c|}{ Perfil T2 - solo com dois anos de cultivo (soja-milho) } \\
\hline Ap & 8,5 & 5,8 & 30,1 \\
\hline $\mathrm{AB}$ & 8,6 & 3,9 & 32,3 \\
\hline Bw1 & 8,9 & 3,9 & 30,1 \\
\hline Bw2 & 9,8 & 3,4 & 28,9 \\
\hline Bw3 & 10,4 & 4,3 & 28,0 \\
\hline Bw4 & 10,1 & 3,9 & 25,2 \\
\hline \multicolumn{4}{|c|}{ Perfil T3 - solo com três anos de cultivo ( soja-milho-soja) } \\
\hline Ap1 & 5,9 & 4,2 & 26,4 \\
\hline Ap2 & 6,3 & 3,3 & 28,2 \\
\hline $\mathrm{AB}$ & 6,7 & 2,6 & 30,5 \\
\hline Bw1 & 7,4 & 3,3 & 31,4 \\
\hline Bw2 & 7,7 & 3,9 & 27,8 \\
\hline Bw3 & 7,9 & 4,6 & 25,3 \\
\hline \multicolumn{4}{|c|}{ Perfil Tp - solo com um ano de cultivo após três anos de pousio } \\
\hline Ap & 6,3 & 5,1 & 31,3 \\
\hline $\mathrm{AB}$ & 7,6 & 2,2 & 32,7 \\
\hline Bw1 & 7,1 & 3,3 & 31,7 \\
\hline Bw2 & 7,4 & 3,5 & 31,2 \\
\hline Bw3 & 8,3 & 4,1 & 29,2 \\
\hline Bw4 & 8,2 & 4,1 & 31,4 \\
\hline
\end{tabular}

* Segundo FREITAS et al (1998b).

As alterações na distribuição dos teores de poros permitiu detectar a degradação da estrutura do solo decorrente do manejo inadequado praticado (Tabela 3). Confirma-se a redução, tanto da porosidade total, como das frações relativas aos micro, meso e, principalmente, macroporos no $3^{\circ}$ ano de cultivo. Os macroporos variaram de $29,7 \%$ a $35,4 \%$ no tratamento $\mathrm{Tn}$, reduzindo para valores entre $25,3 \%$ e $31,4 \%$ no tratamento T3. Analisando, ainda, o perfil Tp, observa-se a tendência da porosidade (micro, meso, macro e total) de retornar aos valores próximos aos do perfil Tn, devido, provavelmente, à ação mecânica exercida pelas raízes das plantas.

Curva de retenção de umidade: os dados de retenção de umidade em diversas tensões mostram que ocor- reu um aumento dos teores de água retida nas baixas tensões $(0,01$ e $0,03 \mathrm{MPa})$ nos perfis $\mathrm{T} 1$ e $\mathrm{T} 2 \mathrm{em}$ relação ao perfil Tn (Tabela 2). Esse fato pode ser consequiência do aumento de microporos, sem, no entanto, alterar os valores de porosidade total. Além disso, o acréscimo nos teores de umidade acompanham, inversamente, os valores de densidade global, indicando que, o que está ocorrendo, não é uma alteração no volume total do solo, mas sim nas relações entre micro e macroporos.

A partir do terceiro ano de cultivo (T3), verificou-se uma redução dos teores de água retida nas baixas tensões em relação ao perfil sob mata (Tn), que foi provocado pela diminuição da porosidade total (Tabela 2). Esses resultados confirmam as afirmativas de PREVEDELLO (1996) e KER $\boldsymbol{e t}$ al. (1996), em que a redução da porosidade afeta a retenção de umidade dos solos, sendo conseqüência direta do manejo inadequado. Neste estudo, o nível crítico ocorreu após o terceiro ano de cultivo. Depois do período de pousio, os valores de umidade à baixas tensões retornaram a valores próximos ao perfil sob cerrado nativo, acompanhando a reestruturação física do solo.

Porém, em relação à capacidade de retenção de umidade a altas tensões, os valores de retenção permaneceram praticamente inalterados, pois a retenção de umidade, nessas tensões, está mais relacionada à textura do solo e superfície específica dos minerais do solo, confirmando os resultados obtidos por SALTER \& WILLIAMS (1965) e PETERSEN et al. (1968).

Disponibilidade de água: observa-se através da figura 1, que o solo em questão apresenta uma baixa retenção de água disponível para as plantas em toda profundidade dos perfis estudados, segundo a classificação dada por USDA (1953), apresentando quantidades de água disponível no solo abaixo de $69 \mathrm{~mm} / \mathrm{cm}$. Verificou-se, ainda, que nos tratamentos Tn a T3 as quantidades de água disponível (AD) situaram-se na faixa de 8,0 a $10,0 \mathrm{~mm} / 20 \mathrm{~cm}$, ocorrendo uma exceção no tratamento Tp, no qual o valor cai para $4,5 \mathrm{~mm} / 20 \mathrm{~cm}$. Em seguida, as curvas mostram uma tendência de queda progressiva da água disponível, em função da profundidade, até atingir valores entre 3,0 e $5,0 \mathrm{~mm} / 20 \mathrm{~cm}$, já na última faixa de profundidade. Essa queda se deve, principalmente, à diminuição dos teores de matéria orgânica total no perfil, que, segundo Miller \& Donahue (1990), apud KER et al. (1996), é de suma importância na retenção de água, a qual não é compensada pelo incremento dos teores de argila.

É importante salientar que a A.D. é o volume máximo de água disponível retida no solo para 




Figura 1 - Distribuição de água disponível em função do tempo de uso nos perfis estudados. Tn: solo sob cerrado nativo; T1: solo com um ano de cultivo de soja; T2: solo com dois anos de cultivo (soja-milho); T3: solos com três anos de cultivo (soja-milho-soja) e Tp: solo com um ano de cultivo após três anos de pousio.

as culturas entre as tensões de 0,1 e $1,5 \mathrm{MPa}$, e que, segundo RESENDE (1994), o nível de esgotamento permissível da água disponível do solo varia em função de diversos fatores, entre eles o tipo de solo, e, para se manter a máxima produção de grãos, o nível de esgotamento deve se situar entre 50 e $60 \%$. Associado a esse conceito, se for considerado uma evapotranspiração potencial (ETp) de 5,0mm/dia para a região de Barreiras, percebe-se que para as culturas de milho e soja, a disponibilidade hídrica é suficiente para suprir as necessidades dessas culturas por apenas dois dias sem irrigação; reforçando assim, a importância de se desenvolver sistemas de manejo sustentáveis que preservem e/ou aumentem os teores de matéria orgânica total. Nesse caso, o problema de disponibilidade de água agrava-se nas profundidades maiores do que $20 \mathrm{~cm}$, pois os níveis de A.D. são menores do que $7,0 \mathrm{~mm} / 20 \mathrm{~cm}$ e estão abaixo da zona radicular das culturas utilizadas na Região, demonstrando que nem em profundidade haverá reserva de água disponível para as plantas.

No perfil Tp, observou-se redução no estoque de $\mathrm{AD}$, isto é, somente o período de três anos de pousio não foi suficiente para levar o solo à sua condição de equilíbrio natural (Tn). Aparentemente, esse solo atingiu um novo estado estável, abaixo da condição de cerrado nativo, o qual levou muitos anos para ser alcançado. Como a variável hídrica é um parâmetro real e integrado do comportamento dos efeitos do preparo do solo, tempo de cultivo, teor de carbono orgânico e grau de compactação, pode-se afirmar que os solos sob cultivo degradaram-se muito rapidamente, em termos físicos e de conteúdo de carbono orgânico, e que o período de pousio não foi suficiente para sua recuperação, evidenciando que a atividade agrícola não está sendo manejada de forma adequada e sustentável.

\section{Fracionamento e caracterização da matéria orgânica}

As condições climáticas da área estudada caracterizam-se por uma reduzida amplitude térmica entre o dia e a noite, e entre o inverno e o verão. Os índices pluviométricos são da ordem de 1.200 $\mathrm{mm} /$ ano e concentram-se num curto período chuvoso, contrastrando com estações secas e bem definidas. O período chuvoso coincide com os dias longos e quentes do verão, quando a atividade microbiana é intensa, tornando rápida a decomposição dos restos vegetais. $\mathrm{O}$ período seco coincide com os dias mais curtos e frios do inverno, tornando o processo de humificação mais lento, devido à baixa atividade biológica nesse período.

Observou-se uma alta taxa de humificação (taxa de extração elevada em relação aos teores totais de carbono), pois as quantidades de matéria "leve" são baixas, possivelmente, devido ao efeito das calagens que favoreceram o aumento dos teores de cálcio, com conseqüente aumento da atividade dos microorganismos, principalmente no período chuvoso. Em nenhuma das situações (perfis), foi observado significativo acúmulo de matéria orgânica, comparativamente à condição de cerrado nativo.

Os produtos resultantes da humificação acumularam-se e distribuíram-se nos perfis, indicando a existência de uma imobilização ou biodegradação imediata dos precussores húmicos (substâncias hidrossolúveis, mais precisamente ácidos alifáticos e fenólicos) nos primeiros centímetros superficiais, que, dessa forma, não podem migrar muito em profundidade. De modo geral, constatou-se um aumento progressivo dos ácidos fúlvicos livres, em profundidade, em todos os perfis. Fato também constatado em outras circunstâncias por VOLKOFF et al. (1978) e CUNHA (1992).

Através dos resultados obtidos com o fracionamento das substãncias húmicas (Tabela 4), verificou-se que as diferentes frações variaram umas em relação às outras. Comparados os teores de matéria orgânica entre os perfis sob cultivo e o solo sob vegetação natural, observaram-se menores teores orgânicos nos primeiros centímetros nos solos cultivados. Acredita-se que essa menor quantidade esteja relacionada com a degradação da cobertura vegetal (desmatamentos e queimadas) e aos reduzidos aportes orgânicos, haja vista que esses solos estão sob a influência dos mesmos fatores climáticos (temperatura e precipitação).

Das frações húmicas, a humina representou a maior parte do carbono. Possivelmente, essa humina constitui-se de humina de insolubilização e herdada (DUCHAUFOUR, 1977), o que deve resultar da transformação moderada de alguns com- 
Tabela 4 - Frações do húmus em percentagem relativa do carbono total dos perfis estudados.

\begin{tabular}{llllll}
\hline Horiz. & M.L. AFL & AF & AH & HU & $\begin{array}{c}\text { Carbono Total } \\
\mathrm{g} / \mathrm{kg}^{-1}\end{array}$ \\
& & & \\
\end{tabular}

\begin{tabular}{|c|c|c|c|c|c|c|}
\hline \multicolumn{7}{|c|}{ Perfil Tn - solo sob cerrado nativo } \\
\hline A1 & 0,44 & 8,03 & 16,13 & 18,99 & 56,41 & 16,06 \\
\hline $\mathrm{A} 2$ & 0,57 & 12,68 & 20,37 & 30,63 & 35,75 & 7,02 \\
\hline $\mathrm{AB}$ & 0,74 & 20,83 & 10,79 & 29,65 & 37,99 & 4,08 \\
\hline Bw1 & 0,62 & 23,31 & 12,88 & 24,85 & 38,34 & 3,26 \\
\hline Bw2 & 0,51 & 32,69 & 13,19 & 14,04 & 39,57 & 2,35 \\
\hline Bw3 & 0,31 & 33,54 & 13,02 & 14,59 & 38,54 & 1,92 \\
\hline Bw4 & 0,21 & 40,80 & 4,32 & 20,14 & 34,53 & 11,39 \\
\hline \multicolumn{7}{|c|}{ Perfil T1 - solo com um ano de cultivo de soja } \\
\hline Ap & 0,62 & 9,61 & 14,88 & 15,36 & 59,53 & 10,55 \\
\hline $\mathrm{AB}$ & 0,62 & 15,26 & 13,65 & 14,76 & 55,71 & 6,30 \\
\hline Bw1 & 0,25 & 21,82 & 15,78 & 9,52 & 52,63 & 3,99 \\
\hline Bw2 & 0,19 & 36,47 & 827 & 6,01 & 49,06 & 2,66 \\
\hline Bw3 & 0,22 & 32,77 & 17,48 & 4,92 & 44,61 & 1,83 \\
\hline Bw4 & 0,12 & 32,16 & 13,92 & 6,43 & 47,37 & 1,71 \\
\hline \multicolumn{7}{|c|}{ Perfil T2 - solo com dois anos de cultivo (soja-milho) } \\
\hline Ap & 0,48 & 11,59 & 14,37 & 12,85 & 60,65 & 10,09 \\
\hline $\mathrm{AB}$ & 0,16 & 17,36 & 21,12 & 9,17 & 52,19 & 5,02 \\
\hline Bw1 & 0,12 & 22,67 & 20,04 & 7,30 & 49,87 & 3,97 \\
\hline Bw2 & 0,08 & 24,71 & 21,00 & 5,93 & 48,79 & 3,71 \\
\hline Bw3 & 0,05 & 31,07 & 20,87 & 6,79 & 41,22 & 2,06 \\
\hline Bw4 & 0,05 & 33,73 & 13,60 & 6,51 & 46,11 & 1,69 \\
\hline \multicolumn{7}{|c|}{ Perfil T3 - solos com três anos de cultivo (soja-milho-soja) } \\
\hline Ap1 & 0,46 & 13,43 & 15,12 & 15,28 & 55,71 & 6,48 \\
\hline Ap2 & 0,36 & 29,61 & 19,73 & 10,45 & 39,85 & 5,27 \\
\hline $\mathrm{AB}$ & 0,63 & 24,86 & 22,13 & 7,65 & 44,73 & 3,66 \\
\hline Bw1 & 0,71 & 31,05 & 21,03 & 7,53 & 39,68 & 2,52 \\
\hline Bw2 & 0,79 & 33,02 & 23,14 & 5,55 & 37,50 & 2,16 \\
\hline Bw3 & 0,60 & 34,34 & 15,66 & 6,03 & 43,37 & 1,66 \\
\hline \multicolumn{7}{|c|}{ Perfil Tp - solo com um ano de cultivo após três anos de pousi } \\
\hline Ap & 0,17 & 12,44 & 10,25 & 29,14 & 48,00 & 6,83 \\
\hline $\mathrm{AB}$ & 0,15 & 14,07 & 15,74 & 22,78 & 46,82 & 5,40 \\
\hline Bw1 & 0,06 & 23,40 & 21,71 & 13,98 & 40,85 & 3,29 \\
\hline Bw2 & 0,09 & 27,55 & 21,77 & 12,00 & 38,59 & 2,25 \\
\hline Bw3 & 0,05 & 25,91 & 18,13 & 10,36 & 45,55 & 1,93 \\
\hline Bw4 & 0,06 & 30,82 & 20,75 & 2,51 & 45,86 & 1,59 \\
\hline
\end{tabular}

RVL: Resíduos vegetais leves; AFL: Ácidos fúlvicos livres; AF: Ácidos fúlvicos ligados; AH: Ácidos húmicos; HU: Humina.

postos insolúveis (lignina), que, segundo DUCHAUFOUR (1973), é estabilizada e protegida contra a biodegradação, já que em região de clima contrastado, os compostos húmicos sofrem uma maturação e uma polimerização que lhes rende resistência aos processos de renovação (VOLKOFF $\boldsymbol{e} t$ al. 1978). BOISSEZON (1973), citado por SANTAISABEL (1988), atribui essa estabilidade à insolubilização dessa humina, que, possivelmente, esteja sendo favorecida pelos óxidos de ferro presentes.

O estudo das substâncias húmicas evidenciou uma dinâmica orgânica muito particular: quando se comparou os solos sob cultivo com o solo sob vegetação natural, observou-se sempre uma tendência de aumento da humina e ácidos fúlvicos ligados; observaram-se, também, uma estabilização dos ácidos fúlvicos livres e uma diminuição dos ácidos húmicos ao longo dos perfis. Quando se comparou os dados do fracionamento orgânico entre os solos sob cultivo, observou-se que houve, sempre, uma tendência de aumento dos ácidos fúlvicos ligados e uma ligeira diminuição dos ácidos húmicos quando se passou de 1 ano para 3 anos de uso agrícola. No Tp, observaram-se um aumento dos ácidos húmicos e uma diminuição da humina.

Esses comportamentos, possivelmente, poderiam estar ligados a dois fatores: adição de calcário, que favorece o aumento dos teores de cálcio e a atividade microbiana (DUCHAUFOUR, 1977), o que aceleraria o processo de humificação da matéria orgânica, com conseqüente liberação dos ácidos hidrossolúveis e formação dos ácidos fúlvicos livres, explicando, assim, o aumento destes. Por outro lado, a rotação de culturas, associada aos contrastes climáticos, favoreceria a polimerização dos ácidos húmicos em humina, explicando, dessa forma, a diminuição dos ácidos húmicos e o aumento da humina.

É bastante conhecido o fato de que as substâncias húmicas menos polimerizadas e mais ácidas podem interagir com os argilominerais e formar complexos metálicos, solúveis e insolúveis (DUCHAUFOUR \& LELONG, 1967; SCHINITZER \& KHAN, 1972; VOLKOFF $\boldsymbol{e t}$ al. 1984; KOTTO SAME et al. 1989/90). Entretanto, estas frações menos polimerizadas (ácidos fúlvicos), são as frações húmicas que apresentam o maior volume de cargas elétricas, portanto maior capacidade de troca de cátions. Por outro lado, as frações mais polimerizadas (ácidos húmicos e humina), apesar de atuarem como agente estabilizador da estrutura, apresentam dentre as frações húmicas, um menor volume de cargas elétricas, logo, uma menor capacidade de troca de cátions (KAEMMERER $\boldsymbol{e} t$ al. 1996).

Considerando-se que os teores de argila e matéria orgânica são muito baixos, resultando em solos com baixa capacidade de troca de cátions, o uso de um sistema de manejo mais racional (cultivo mínimo, plantio direto, rotação de culturas, etc) poderia favorecer um processo de humificação menos intenso, no qual se teriam, em quantidades equivalentes, substâncias húmicas menos polimerizadas para a obtenção de uma maior quantidade de cargas elétricas; e outras mais polimerizadas que pudessem favorecer a formação e estabilização de unidades estruturais e, dessa forma, maximizar a retenção de água, a manutenção do conteúdo de carbono orgânico e o aumento da produtividade das culturas. 


\section{CONCLUSÕES}

O sistema de manejo convencional provocou mudanças nas propriedades edáficas estudadas, acarretando restrições ao sistema já no terceiro ano de uso agrícola. As propriedades físicas de densidade do solo, porosidade e água disponível foram fortemente influenciadas pelo sistema de manejo.

O tempo de pousio de três anos não foi suficiente para recompor ao sistema as características edáficas observadas no perfil sob vegetação de cerrado nativo, principalmente, em termos de conteúdo e qualidade da matéria orgânica, e conteúdo de água disponível.

O sistema de manejo estudado, com o tempo de uso, favoreceu o aumento de ácidos fúlvicos e de humina e uma diminuição de ácidos húmi$\cos$.

\section{REFERÊNCIAS BIBLIOGRÁFICAS}

BLANCANEAUX, Ph., FREITAS, P.L. de, AMABILE, R.F., $\boldsymbol{e}$ al. Le semis direct comme pratique de conservation des sols des cerrados du Brésil central. Cahiers Orstom, série Pédologie, Paris, v.28, n.2, p.253-275, 1993.

CUNHA, T.J.F. Matéria orgânica de alguns solos de Irecê, Ba: sua dinâmica e algumas relações pedogenéticas. Salvador, 1992. 221p. Dissertação (Mestrado em Geociência) - Curso de Pós-graduação em Geociência, área de concentração em pedologia, Instituto de Geociência-IGG-UFBA, 1992

DABIN, B. Étude d`une métode de fractionnement des matière humiques du sol. Science du Sol, Versailles, v.1, p.47-63, 1971.

DALlA ROSA, A. Práticas mecânicas e culturais na recuperação de características físicas de solo degradado pelo cultivo no solo Santo Ângelo: Latossolo roxo distrófico. Porto Alegre : UFRGS - Faculdade de Agronomia, 1981. 138p. Dissertação (Mestrado em Agronomia, área de concentração Solos, setor Uso e conservação de solos) - Curso de Pósgraduação em Agronomia, Faculdade de Agronomia, Universidade Federal do Rio Grande do Sul, 1981.

DUCHAUFOUR, Ph., LELONG, F. Entrainement ou destruction d`argile dans les horizons éluviaux de sols lessivés. Comptes Rendus Hebdomadaires des Seances de l' Academie des Sciences, serie D, Paris, v.264, p.2884-2887, 1967.

DUCHAUFOUR, Ph. Action des cations sur les processus d`humification. Science du Sol, Versailles, v.3, p.151-161, 1973.

DUCHAUFOUR, $\mathrm{Ph}$. Pédogenése et classification. In: DUCHAUfOUR, Ph., SOUCHIER, B., ed. Pedologie. Paris : Orstom, 1977. v.1, 478p.

EMBRAPA. Centro Nacional de Pesquisa de Solos (Rio de Janeiro, RJ). Manual de métodos de análise de solo. 2.ed. rev. atual. Rio de Janeiro, 1997. 212p. (EMBRAPA-CNPS. Documentos, 1).
ESTADOS UNIDOS. Department of Interior. Bureau of Reclamation. Irrigated land use: land classification. Denver, 1953. v.5, part 2.

FREITAS, P.L. de. Manejo Físico do Solo. In: SIMPÓSIO SOBRE MANEJO E CONSERVAÇÃO DO SOLO NO CERRADO, 1, 1990, Goiânia, GO. Anais... Campinas : Fundação Cargill, 1992. p.117-139.

FREITAS, P.L. de, BLANCANEAUX, Ph. Estrutura e porosidade do solo. In: PUIGNAU, J. (ed.) Metodologias para investigacion en manejo de suelos. Montevidéu : IICAPROCISUR, 1994. p.25-42. (Diálogo/IICA-PROCISUR, $39)$.

FREITAS, P.L. de, BLANCANEAUX, Ph., FELLER, C. Efeito de diferentes sistemas de manejo do solo no nível e na natureza do estoque orgânico dos solos de Cerrados. Pesquisa Agropecuária Brasileira, Brasília, 1998a [no prelo, registro n. 97.225].

FREITAS, P.L. de, BLANCANEAUX, Ph., MOREAU, M. Caractérisation structurale de sols des Cerrados Brésiliens (Savanes) sous différents modes d'utilisation agricole. Etude et Gestion des Sols, Paris, v.5, n.2, p.93-105. 1998b.

JUCKSCH, I., COSTA, L.M. da, MOURA FILHO, W., et al. Efeito da calagem na dispersão de argila em um latossolo vermelho-escuro. Revista Ceres, Viçosa, v.33, n.189, p.456460 .

KAEMMERER, M., GUIRESSE, M., BAILLY, J.R., $\boldsymbol{e}$ t al. Influência de las substâncias húmicas sobre las características bio-fisico-quimica de lkos suelos. Consequencia sobre la nutrición mineral de las plantas. In: CONGRESSO LATINO AMERICANO DE CIÊNCIA DO SOLO, 13; REUNIÃO BRASILEIRA DE BIOLOGIA DO SOLO, 1; SIMPÓSIO BRASILEIRO SOBRE MICROBIOLOGIA DO SOLO, 4; REUNIÃO BRASILEIRA SOBRE MICORRIZAS, 6; REUNIÃO BRASILEIRA DE MANEJO E CONSERVAÇÃO DO SOLO E DA ÁGUA, 11, 1996, Águas de Lindóia, SP. Solo-Suelo 96... Piracicaba : USP-ESALQ / Sociedade Brasileira de Ciência do Solo / Sociedade Latinoamericana de Ciência do Solo, 1996. CD-ROM.

KER, J.C., MARCIANO, L., SILVA, A.B. da, et al. Classificação e manejo dos solos em áreas irrigadas: curso de engenharia e manejo de irrigação: modulo 5. Brasília : ABEAS / Viçosa : Universidade Federal de Viçosa, 1996. 140p.

KIEHL, E.J. Manual de edafologia: relação solo-planta. São Paulo: Agronômica Ceres, 1979. 264p.

KOTTO SAME, J., BITON, D., VOLKOFF, B. Matière organique et transformations structurales superficielles dans un sol ferrallitique rouge de la zone forestiere de Cameroun. Cahiers ORSTOM, serie Pedologie, Paris, v.25, n.3, p.231$241,1989 / 90$.

LEMOS, R.C., SANTOS, R.D.dos. Manual de descrição e coleta de solo no campo. 2.ed. Campinas: Sociedade Brasileira de Ciência do Solo / EMBRAPA- SNLCS, 1984. 45p.

MACHADO, J.A., PAULA SOUZA, D.M., BRUM, A.C.R Efeito de anos de cultivo convencional em propriedades físicas do solo. Revista Brasileira de Ciência do Solo, Campinas, v.5, n.3, p.187-189, 1981. 
PEREIRA, V.de P., FERREIRA, M.E., CRUZ, M.C.P. Solos altamente suscetíveis à erosão. Jaboticabal : UNESP-FCAV / Sociedade Brasileira de Ciência do Solo, 1994. 45p.

PETERSEN, G.W., CUNNINGHAM, R.L., MATELSKI, R.P. Moisture characteristics of Pennsylvania soils. I. Moisture retention as related to texture. Soil Science Society of America Proceedings, Madison, v.32, n.2, p.271-275, 1968.

PREVEDELLO, C.L. Física do solo com problemas resolvidos Curitiba : Sociedade Autônoma de Estudos Avançados em Física do Solo, 1996. 446p.

RESENDE, M. Manejo de Irrigação. In: CURSO DE USO E MANEJO DE IRRIGAÇÃO, 11, 1994, Sete Lagoas, MG. Apostila... Sete Lagoas : EMBRAPA-CNPMS, 1994. 36p.

ROOSE, E., BLANCANEAUX, Ph., FREITAS, P.L. de. Un simple test de terrain pour évaluer la capacité d'infiltration et le comportement hydrodynamique des horizons pédologiques superficiels: méthode et exemples. Cahiers ORSTOM, serie Pedologie, Paris, v.28, n.2, p.413-419, 1993.

SALTER, P.J., WILLIAMS, J.B. The influence of texture on the moisture characteristics of soils. I. A critical comparison of techniques for determining the available-water capacity and moisture characteristic curve of a soil. Journal of Soil Science, Osney Mead, v.16, n.1, p.1-15, 1965.
SANTA-ISABEL, L.M. Caracterização e algumas relações pedogenéticas da matéria orgânica de uma toposseqüência de solos em região de clima semi-árido de Itaberaba, BA. Salvador, 1988. 175p. Dissertação (Mestrado em Geociência, área de concentração em Pedologia) - Curso de Pós-graduação em Geociência, Instituto de Geociência-IGGUFBA, 1988

SCHINITZER, M., KHAN, S.U. Humic substances in the environment. New York : Marcel Dekker, 1972. 327p.

SILVA, I.F.da, MIELNICZUK, J. Avaliação do estado de agregação do solo afetado pelo uso agrícola. Revista Brasileira de Ciência do Solo, Campinas, v.21, n.2, p.313-319, 1997.

SOUZA, L.S., COGO, N.P. Caracterização física em solo da unidade de mapeamento São Jerônimo-RS (Paleudult), em três sistemas de manejo. Revista Brasileira de Ciência do Solo, Campinas, v.2, n.3, p.170-175, 1978.

VOLKOFF, B., CERRI, C.C., MELFI, A.J. Húmus e mineralogia dos horizontes superficiais de três solos de campo de altitude dos Estados de Minas Gerais, Paraná e Santa Catarina. Revista Brasileira de Ciência do Solo, Campinas, v.8, n.3, p.277-283, 1984.

VOLKOFF, B., FLEXOR, J.M., SANTA-ISABEL, L. M., et al. Natureza do húmus nos Latossolos distróficos da Bahia. Revista Brasileira de Ciência do Solo, Campinas, v.2, n.1, p.59-63, 1978.

Ciência Rural, v. 31, n. 1, 2001. 